University of South Carolina

Scholar Commons

Summer 1988

\title{
Neighborhood Differences in Attitudes toward Policing: Evidence for a Mixed-Strategy Model of Policing in a Multi-Ethnic Setting
}

Roger G. Dunham

Geoffrey P. Alpert

University of South Carolina - Columbia, geoffa@mailbox.sc.edu

Follow this and additional works at: https://scholarcommons.sc.edu/crim_facpub

Part of the Law Enforcement and Corrections Commons

Publication Info

Published in Journal of Criminal Law and Criminology, Volume 79, Issue 2, Summer 1988, pages 504-523. Dunham, R. and Alpert, G. (1988). Neighborhood Differences in Attitudes toward Policing: Evidence for a New Approach to Policing in a Multi-Ethnic Setting. Journal of Criminal Law and Criminology, 79(2), 504-523.

Copyright () by Northwestern University, School of Law.

This Article is brought to you by the Criminology and Criminal Justice at Scholar Commons. It has been accepted for inclusion in Faculty Publications by an authorized administrator of Scholar Commons. For more information, please contact digres@mailbox.sc.edu. 


\title{
CRIMINOLOGY
}

\section{NEIGHBORHOOD DIFFERENCES IN ATTITUDES TOWARD POLICING: EVIDENCE FOR A MIXED-STRATEGY MODEL OF POLICING IN A MULTI-ETHNIC SETTING}

\author{
ROGER G. DUNHAM* \\ GEOFFREY P. ALPERT**
}

There are prevalent in society two general conceptions of the duties of the police officer. Middle class people feel that he should enforce the law without fear or favor. Cornerville people and many of the officers themselves believe that the policeman should have the confidence of the people in his area so that he can settle many difficulties in a personal manner without making arrests. These two conceptions are in a large measure contradictory. ${ }^{1}$

William Foote Whyte made these general observations more than forty years ago in Street Corner Society. The sharply contrasting social pressures that existed in different neighborhoods were important consequences of urban life. Whyte noted, more specifically, that the police must adapt to these different standards of acceptable conduct prevalent in different neighborhoods. ${ }^{2}$ His observations have been echoed by many, ${ }^{3}$ but tested by few. Other researchers have continued Whyte's theme that in the context of community policing, effective policing requires an understanding of the different citizens' expectations and values toward police practices. ${ }^{4}$

* Associate Professor, Department of Sociology, University of Miami

** Professor, College of Criminal Justice, University of South Carolina

1 W. Whyte, SReet Corner Society, 136 (1943).

2 Id. at 138.

3 See A. Reiss, Jr., The Police and the Public (1975); J. Wilson, Varities of PoLICE BEHAVIOR (1968).

4 See J. Wilson \& G. Kelling, Broken Windows: The Police and Neighborhood Safety, 249 Atlantic Monthly (March, 1982) 29-38; and P. Manning, Community Policing, in Policing America (R. Dunham \& G. Alpert ed.) (in press). 
After a substantial amount of police research during the 1960's, there has recently occurred a resurgence of interest concerning how the police respond in different neighborhood contexts. ${ }^{5}$ However, much of the emphasis of this research has been on how the police categorize the "good" and "bad" areas or neighborhoods, and discriminate against citizens in the "bad" areas with a process of ecological contamination. ${ }^{6}$ The police react as if everyone in the "bad" areas are suspect, and treat them more harshly.

Lawrence Sherman argues that depending on the neighborhood there is considerable variation in the way the police manage resources, exercise discretion, and decide when to respond to problems. ${ }^{7}$ Yet, he concludes there is little relativity in basic police strategy. ${ }^{8}$ Due to this, Sherman argues for a mixed strategy model to policing particular communities based upon their unique characteristics. ${ }^{9}$ Unfortunately, there is little empirical data assessing the assumption that residents of neighborhoods or communities have distinct preferences or dislikes for specific police strategies or practices. Indeed, it is unclear whether these preferences or dislikes vary from one type of neighborhood to another.

The purpose of this Article is to examine the differences in agreement and disagreement with various police practices among the residents of ethnically distinct neighborhoods in Miami, Florida. The findings provide needed empirical evidence for determining whether William F. Whyte was correct, and whether significant differences among neighborhoods really do exist. Further, these findings can guide police training to meet citizens' expectations for acceptable and effective policing. Research comparing ethnically distinct neighborhoods has not fully examined this aspect of neighborhood influences on policing.

This Article will show that communities vary considerably in residents'expectations for police services. Residents of various culturally distinct neighborhoods may have different values dictating

5 See J. Skolnick \& D. Bayley, The New Blue Line: Police Innovation in Six American Cities (1986); R. Taub, D. Taylor \& Y. Dunham, Paths of Neighborhood Change: Race and Crime in Urban America (1984); Decker, Citizens' Attitudes Toward the Police: A Review of Past Findings and Suggestions for Future Policing 9 J. Pol. Sci. \& Admin. 80-87 (1981); Jacob, Black and White Perceptions of Justice in the City 6 LAw \& Soc'y Rev. 69 89 (1971); Sherman, Policing Communities: What Works?, Communities \& Crime 343-86 (1986); Smith, A Neighborhood Context of Police Behavior, Communities \& Crime 313-41 (1986).

6 These studies view neighborhood context as the independent variable affecting how the police use their discretion.

7 Sherman, supra note 5, at 344-46.

8 Id. at $346-47$.

9 Id. at $379-80$ 
the appropriateness of police behavior and of the policing styles used in specific situations. These preferences and dislikes may be interwoven into the fabric of the culture, the attitudes toward general authority, and more specifically toward police authority. In turn, police strategies and practices incongruent with the basic culture and values of a neighborhood would likely be ineffective and perhaps even counterproductive to maintaining order and controlling crime.

\section{The Effect of Neighborhood Characteristics on Policing}

It is apparent that neighborhood differences are important to effective policing, and that the police routinely operate differently in some specific ways in response to neighborhood differences. It is unfortunate that there are insufficient data to aid police in responding appropriately. This Article will examine how residents of different neighborhoods evaluate specific police practices. Several studies are directly relevant to this research in that they examine specific neighborhood differences in attitudes toward the police and policing.

Two important studies deserve particular attention. First, Schuman and Gruenberg concluded that the primary factor explaining satisfaction and dissatisfaction with police services is the neighborhood. ${ }^{10}$ They found race to be an important factor as well, but race variation was largely accounted for by the neighborhood. ${ }^{11}$ Apparently, the interaction between race and neighborhood accounts for much of the variation in attitudes toward the police and police services. Second, Walker and his colleagues also found neighborhood context to be an extremely important factor in attitudes toward the police and, more specifically, in the amount of support residents give to the police. ${ }^{12}$ Walker found that involuntary contacts with the police contributed to the more negative attitudes exhibited by blacks toward the police. ${ }^{13}$ However, they found that the nature of the contact and the cumulative contextual effect within the neighborhood best accounted for the low level of support for the police reported among blacks.

This Article goes beyond these research findings to examine

10 Shuman \& Greenberg, Dissatisfaction with City Services: Is Race an Important Factor?, People \& Pol. URB. Soc'y 386-87 (1972).

11 Id. at 386.

12 Walker, Richardson, Denyer, Williams, \& McGaughey, Contact and Support: An Empirical Assessment of Public Attitudes Toward the Police and the Courts, 51 N.C.L. Rev. 43-79 (1972) [hereinafter Walker].

13 Id. at 65 . 
more directly attitude differences in five culturally distinct neighborhoods. Research on attitudes towards police practices typically uses samples combining various and diverse social groups to represent large populations. While this approach can be used to characterize whole geographical areas, it may mask the unique attitudes of the various social groups. ${ }^{14}$ In turn, findings resulting from attempts to characterize generalized attitudes of an entire population are of limited use to police planners and trainers, since the police must respond to the needs and concerns of citizens that are often unique to particular cultural groups. Neighborhoods are important to police because police are deployed to them. This is especially important when neighborhoods are ethnically homogeneous. In these cases, police deployment is, accidently or by design, partially ethnic specific.

Given the mixed social character of our cities and the mosaic that makes our social fabric, police administrators must decide how to prepare officers to function effectively in the many diverse cultural environments they serve.

\section{Methods and Procedures}

The present article involves a sample of neighborhoods in Miami, Florida and a sample of individuals within those neighborhoods. Each sample was chosen to allow for the most advantageous study of the issues central to our concerns: the relationships between the police and communities. The sample of neighborhoods allows for comparisons between areas with high versus low crime rates and distinct ethnic and social class compositions. Within each neighborhood, the survey data allows for study of how individual attitudes and values towards various policing practices form the aggregate patterns unique to each neighborhood.

\section{A. NEIGHBORHOOD SAMPLES}

Neighborhoods were selected because of their uniqueness, rather than to represent a balanced cross section of Miami or Dade County, Florida. Indeed, the overall population of Dade County is so segmented by ethnicity and social class that any overall characterization of the population would be difficult, if not impossible. With the assistance of police officials, officials from the Dade County

14 See Sullivan, Dunham \& Alpert, Attitude Structures of Different Ethnic and Age Groups Concerning the Police and Police Procedures, 78 J. Crim. L. \& Criminology 177-196 (1987); Scaglion and Condon, The Structure of Black and White Attitudes Toward Police, 39 Hum. Organization 280 (1980). 
Planning Department, and the 1980 census data, five neighborhoods, each representing a meaningful geographic unit to the police units operating in these areas, were chosen.

\section{Rolling Oaks}

Rolling Oaks is a relatively small community of about 150 recently built homes. Nearly all of the residents are upper-middleclass black professionals. Every third house was studied to complete a sample of fifty households.

\section{James Scott Housing Project}

The James Scott Housing Project is a government subsidized housing project populated almost exclusively by low income blacks. There are a total of 858 units, most of which are occupied. ${ }^{15}$ Every sixteenth unit was surveyed to complete a sample of fifty units.

\section{1960 Cuban Entrants}

The third neighborhood is a combination of middle-class and working-class homes that contain a very high percentage of Latin residents, most of whom are Cubans who immigrated during the first wave of Cuban immigration in the 1960s. There were nearly 700 homes in the neighborhood, and every fourteenth residence was surveyed to yield a sample of fifty residences.

\section{1980 Cuban Entrants}

The procedure used to sample the fourth neighborhood represents an attempt to identify the attitudes of a new group of Cuban immigrants in the Miami area. Officials from the planning department identified a neighborhood of Cubans who arrived in this country during the 1980 boatlift. Interviewers screened prospective subjects and interviewed only those who immigrated from Cuba during the 1980 Mariel Boatlift.

\section{Kendall Area}

The fifth neighborhood is a well established anglo middle and upper-middle-class area. There are about 900 houses in the particular Kendall neighborhood chosen, and every eighteenth home was surveyed to yield a total of fifty homes.

A sampling procedure was developed to select the member of the household to be interviewed to insure a representative sample of

15 Of the 858 units, $837(98 \%)$ are occupied. 
individuals living within households. Interviewers sampled only adults 18 years of age or older. Interviewers asked the number of adults and the number of men and women living in the house. The interviewer then used a table of random selections to decide which adult to interview. ${ }^{16}$ Provisions were made for the inability to contact the selected person after two visits. Substitutions of an underrepresented group were allowed for, but such substitutions were made in less than $15 \%$ of the houses. The procedure also called for substituting houses after an unsuccessful second visit. The interviewer was instructed to go first to the house on the right and then to the one on the left. This was not a very important factor, as the neighborhoods were so homogeneous.

\section{Measures}

In order to determine the attitudes towards policing practices held by the residents of the neighborhoods selected, an exhaustive review of the research literature was conducted. There are numerous studies on the interrelationship between the police and the community, with numerous arrays of questions concerning attitudes toward policing. We selected scales and sets of questions that were relevant to our research that had withstood the test of time with regard to reliability and the validity of testing. This resulted in thirty questions coming from a variety of attitude scales: Hostility Index, Attitudes Toward the Police Questionnaire, Perceptions of Police Scale, Citizens Perception of Police, ${ }^{17}$ Police Aggressiveness Scale, Selectiveness of Law Enforcement, Perceived Limits on Discretion and Perception of Supervisor's Behavior, Patrolman's and Supervisor's Attitudes Toward Priorities, Patrolman's and Supervisor's Attitudes Toward Aggressiveness, Patrolman's and Supervisor's Attitudes Toward Order-Maintenance. ${ }^{18}$ The thirty questions were scored on a one to five Likert-type scale. A "one" signified strong agreement. A "two" represented agreement, a "three" meant undecided, a "four" signified disagreement, and a "five" represented strong disagreement.

\section{Factor Analysis}

In the present study, these thirty items were administered to a sample of 451 high school students and to a sample of 296 Dade

16 For example, the table might call for the oldest man living at the residence.

17 Brodsky \& Smitherman, Handbook of Scales for Research, Crime \& Deline. 43-96 (1983).

18 M. Brown, Working the Street: Police Discretion and the Dilemmas of Police Work 310-12 (1981). 
County police officers, in addition to the study population of 250 Dade County residents. The data from the additional samples were used to provide a wide variety of respondents for scale construction.

The expectation was that certain, specific attitudinal domains would emerge from the combination of the 997 subjects. An effort was made to reduce the total number of items, eliminate those which were highly correlated, and identify the concepts which were believed to be the most important by the subjects. In other words, there was a search for attitude domains which can be identified by groups of questions which are answered in patterned ways. The factor analytic technique to detect such patterned deviations from the grand mean was chosen because individuals do not agree exactly concerning their judgments about police practices. This technique aided in identifying the sets of question which represent the most significant attitudinal domains.

Clearly patterned deviations will produce a much smaller number of factor dimensions than loosely patterned deviations using an analysis of both slope and response level. If the patterns of deviation in the data pertain mainly to the level of response, all the stimulus values in a continuum ought to load on the same factor. This indicates that if an individual has a higher score than the group mean on one question, that he or she will tend to be high on all of the questions. If, on the other hand, slope differences predominate, the stimulus values from the extremes of a continuum should load in opposite directions, because a person who was higher than the group mean in the high range should also be lower than the group in the low range.

A separate factor analysis was completed for each of the populations, citizens, police, and students, to find out if the items would factor the same for each group so that the groups could be combined requiring one overall factor analysis. Some differences were found, but they were so minor that combining the samples was justified. In addition, a separate factor analysis was completed for ethnic groups and age groups. ${ }^{19}$ This analysis resulted in the finding that although there were many similarities in the cognitive structures of members of the various groups, the attitudes toward the police are structured differently for these groups. However, the greatest differences were between age groups, such as teens and adults.

To investigate more specifically the attitudes of each of the ethnic groups, one should examine the unique conceptualizations of each group. However, since the data include only adults, and the

19 See Sullivan, Dunham \& Alpert, supra note 14. 
purposes of the study involve general comparisons between groups, more general measures are appropriate. The resulting overall factor analysis generalizes to the several different populations.

A factor analysis with a varimax rotation was performed on the scores of the thirty questions for the total sample. The factor analysis for the total sample, 977, revealed five factors, or attitudinal domains, which included items with factor loadings greater than .50 . There are two factor loadings, however, that are just under our .50 cut off point (.47) that are included in factors three and five. These two exceptions were made because of the questions' conceptual congruence with the factors and because they were just below the cut off limit. ${ }^{20}$

\section{The Five Scales}

Demeanor: This scale consists of eight questions which measure the subject's perceptions of the general demeanor of police officers or his orientation toward citizens. Specific questions illicit responses concerning courteousness, friendliness, rudeness and concern or respect for citizens displayed by police officers. This scale includes the eight questions measuring specific behaviors representing a comprehensive measure of police officer demeanor. The lower the score, the stronger the perception of a positive demeanor.

The inter-item correlations for the questions in this scale are quite low, indicating the independence of the questions. ${ }^{21} \mathrm{An} \mathrm{Al}-$ pha of .88 for this scale indicates a high reliability.

Responsibility: This scale consists of two questions concerning the role of the police and citizens in controlling crime: "only the police can control crime in Dade County/my neighborhood." The lower the score, the stronger the agreement with the statement that most of the responsibility for controlling crime rests with the police. The inter-item correlation for this scale is . 55 , and the Alpha is .71.

Discretion: Two questions are involved in this scale, which measures agreement with the need for variability in enforcing the law, and especially in stretching procedural safeguards ${ }^{22}$ in some neighborhoods or areas. The lower the score, the stronger the agreement with the need for variability in enforcement and in applying procedural safeguards. The inter-item correlation for this scale is .27 , while the Alpha is quite low, equalling .43. Further analysis of the

20 See Appendix A.

21 See Appendix B.

22 These are the procedural safeguards that police follow to insure the rights of alleged offenders are protected. 
reliability of this scale revealed that the reliabilities for two of the neighborhoods were extremely low: .03 for James Scott and .12 for the 1980 Cuban immigrants. Apparently, this scale did not represent the way the poor blacks and the recent Cuban immigrants conceptualize police use of discretion. Interpretation of the scores on this scale in those two neighborhoods must be made with caution.

Ethnic: This scale consists of three questions concerning the justification for the suspicion that certain ethnic groups are more crime prone. The three questions are identical except each makes reference to a different ethnic group: black, hispanic and anglo. The lower the score, the stronger the agreement with the idea that certain ethnic groups need to be watched more closely than others. The inter-item correlations are quite low, [anglo/black $=.23$, black/hispanic $=.29$, anglo/hispanic $=.52$,] indicating the independence of the questions. The Alpha is moderate at .62.

Patrol: Two questions comprise this scale, which measures the approval of active patrol strategies, such as stopping and questioning people walking down the street and stopping cars for random checks. The lower the score, the stronger the agreement that active patrol strategies are appropriate and necessary to control crime. The inter-item correlation is .49 , and the Alpha is .66 .

Findings

These scales represent five very different yet interlocking attitude domains concerning police strategies and practices.

The first concern is with the variability among neighborhoods on each of the five scales in relation to the variance within neighborhoods. This is used to determine whether there is more variance among neighborhoods than within neighborhoods. Second, any significant differences in scale scores between males and females, among ethnic groups, and their relationship to family income are examined. Social class and ethnicity, potentially the two major contaminating factors in this analysis, are controlled naturally by the research design, through the selection of neighborhoods. ${ }^{23}$ Therefore, these variables do not need to be controlled statistically. There is almost no variation within neighborhoods on these two variables. However, all neighborhood samples are combined to observe the overall effects of ethnicity and social class on the scale scores. Family income is used as an indicator of social class. Finally, a comparison is made between the neighborhoods and the relative homogeneity of attitudes and values.

23 R. Dunham \& G. Alpert, Policing Multi-Ethnic Neighborhoods 41-47 (1988). 
Instead of using the absolute magnitudes of the standard deviations, coefficients of relative variation (CRV) were calculated, which control for variation in the size of the means. The CRV is merely the standard deviation divided by the group mean, and can be interpreted as a standard deviation that is further standardized by the size of the mean. The lower the CRV, the greater the degree of cohesiveness within the group. This measure allows for determination of the relative cohesiveness, relative to the other groups, of opinions and values within each neighborhood on each of the scales. In addition, the relative cohesiveness of attitudes about each of the five scale constructs within the entire population of subjects can be determined.

The data in Table 1 summarize the scores on the Demeanor scale for each of the neighborhood samples as well as for ethnic groups. Overall, the perception of police demeanor is slightly in the positive direction. A "one" signifies strong agreement with a positive statement about police demeanor. A "two" represents agreement, a "three" means undecided, a "four" signifies disagreement and a "five" represents strong disagreement. All of the means are less than three or in the agreement range.

TABLE 1

SCORING ON THE Demeanor SCALE BY NeIGHBorhood AND ETHNICITY

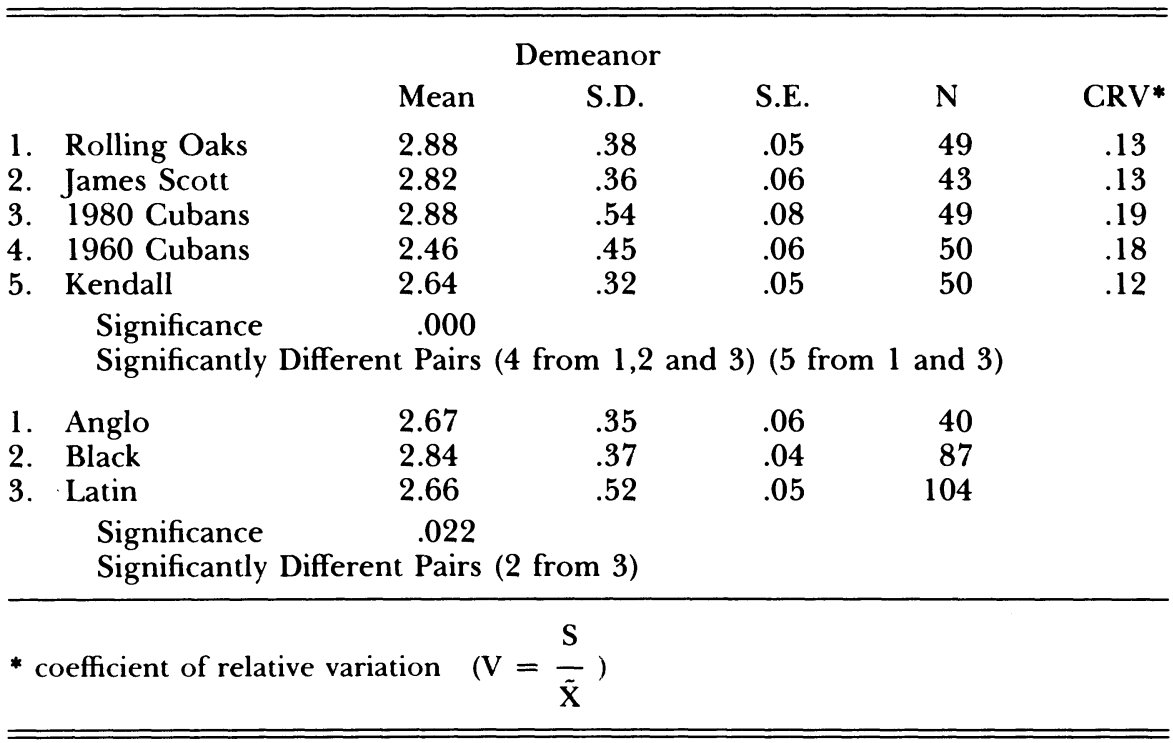

The 1960 Cuban immigrants perceive police demeanor the 
most positively. Kendall residents view police demeanor more positively than the remaining groups, but not nearly as much as the 1960 Cubans. The two black neighborhoods and the 1980 Cubans reported the most negative responses toward police demeanor. There is no significant difference between males and females on this scale. There are small but statistically significant differences between ethnic groups and perceptions of police demeanor. Anglos and Cubans gave more positive evaluations of police demeanor than did blacks. The relationship between family income and scores on the demeanor scale is significant, .053 , but weak, with $r=.112$.

The significant main effect obtained from the analysis of variance indicates that the variance is more pronounced between neighborhoods than within neighborhoods. The CRV analysis indicates that all of the neighborhoods are quite cohesive concerning attitudes about police demeanor, relative to the cohesiveness of groups on the other scales. In fact, each neighborhood had more internal cohesiveness on police demeanor than on any of the other attitude domains.

Thus, there is not a drastic amount of variance among groups on the demeanor scale. All of the groups report attitudes in a positive direction, with the 1960 Cubans and the Kendall residents holding the most positive perceptions of police demeanor. There is not any evidence showing a need to develop specific neighborhood strategies concerning police demeanor.

The data in Table 2 summarize the scores on the Responsibility scale. There are clear differences among neighborhoods as to whether the major responsibility for controlling crime lies with the police. The two Cuban groups agree with this notion while all of the other groups disagree. Further, of those groups that disagree, the Kendall residents report the strongest disagreement. Not only do the Kendall residents report the strongest disagreement, but they also have the highest level of consensus, as indicated by a comparison of the CRVs. In contrast, although the two Cuban groups are the only groups agreeing that the police are solely responsible for crime control, they have the lowest level of concensus.

There is no significant difference between males and females on this scale, and its relationship with family income is not significant. The breakdown of the three ethnic groups indicates that the Cubans were the only ones to agree with the idea that the major responsibility for crime control rests with the police. All others disagreed. The Anglo respondents reported the strongest disagreement. With the exception of the Kendall residents, each neighborhood group re- 
TABLE 2

SCORING ON THE RESPONSIBILITY SCALE BY NEIGHBORHOOD AND ETHNICITY

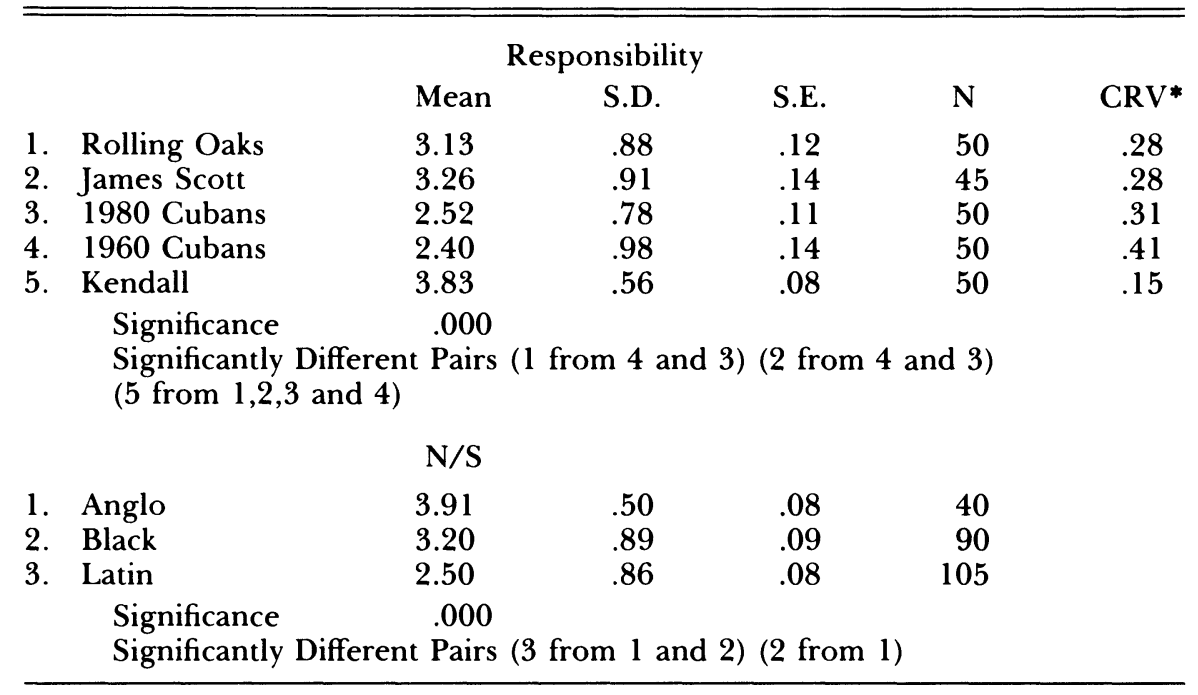

* coefficient of relative variation $\left(\mathrm{V}=\frac{\mathrm{S}}{\tilde{\mathrm{X}}}\right)$

ported lower levels of consensus on the responsibility scale when compared to the other four scales.

In summary, there are considerable differences among the groups concerning agreement with the notion that only the police should contol crime. The residents of both Cuban neighborhoods agree, while all the other groups disagree. Kendall residents had not only the strongest disagreement, but also the most consensus. After combining all these groups to assess ethnic differences, Cubans remain the only group to agree, while Anglos have the strongest disagreement.

The data in Table 3 summarize the scores on the Discretion scale for each of the samples. The general sentiment among all groups is that police should use considerable discretion when applying procedural safeguards and other procedures in the different neighborhoods. The respondents in both of the Cuban neighborhoods gave the strongest approval for the use of discretion, and the residents of Rolling Oaks gave the weakest level of approval. Even these lower scoring groups, however, still approve of the use of discretion. They simply approve of it less empathetically than the other groups. Due to the low reliability coefficients of this scale for two of our 
TABLE 3

Scoring ON THE Discretion SCALE by Neighborhood AND ETHNICITY

\begin{tabular}{|c|c|c|c|c|c|c|}
\hline \multicolumn{7}{|c|}{ Discretion } \\
\hline & & Mean & S.D. & S.E. & $\mathrm{N}$ & $\mathrm{CRV}^{*}$ \\
\hline 1. & Rolling Oaks & 2.71 & .73 & .11 & 48 & .27 \\
\hline 2. & James Scott & 2.55 & .67 & .11 & 39 & .26 \\
\hline 3. & 1980 Cubans & 2.03 & .52 & .07 & 49 & .26 \\
\hline 4. & 1960 Cubans & 1.86 & .61 & .09 & 50 & .33 \\
\hline 5. & Kendall & 2.22 & .66 & .09 & 50 & .30 \\
\hline \multirow{2}{*}{\multicolumn{7}{|c|}{$\begin{array}{l}\text { Significance } \quad .000 \\
\text { Significantly Different Pairs (1 from 3,4 and 5) (2 from } 4 \text { and 3) (5 from 4) }\end{array}$}} \\
\hline & & & & & & \\
\hline 1. & Anglo & 2.21 & .71 & .11 & 40 & \\
\hline 2. & Black & 2.63 & .69 & .08 & 82 & \\
\hline 3. & Latin & 1.96 & .56 & .05 & 104 & \\
\hline \multirow{2}{*}{\multicolumn{7}{|c|}{$\begin{array}{ll}\text { Significance } & .000 \\
\text { Significantly Different Pairs (2 from land 3) }\end{array}$}} \\
\hline & & & & & & \\
\hline
\end{tabular}

* coefficient of relative variation $\left(\mathrm{V}=\frac{\mathrm{S}}{\tilde{\mathrm{X}}}\right)$

neighborhoods, James Scott and the 1980 Cuban immigrants, interpretation of these findings is only suggestive and tentative.

As in the demeanor and responsibility scales, gender was not a significant factor. Family income was significantly related to scores on this scale, .019 , but the relationship is very weak, with $\mathrm{r}=.143$. When combining all groups, the blacks reported the weakest level of approval for the use of discretion in comparison to the Anglos and Latins.

Thus, there is more overall agreement in attitudes toward police use of discretion than for any of the other scales. The two Cuban groups report the strongest agreement, while residents of Rolling Oaks showed the weakest agreement. blacks, in general, showed the weakest level of agreement. Analysis of the CRVs indicates a moderate level of consensus within groups that is quite evenly distributed among the groups.

The data in Table 4 summarize the scores for the Ethnic Suspicion scale. Generally, all of the study groups, except one, disapproved of the notion that some ethnic groups need to be watched more closely for criminal activity than others. The one exception is the James Scott project. The mean score for this group indicates that these respondents either agreed or were undecided about the need to have police watch some ethnic groups more closely than 
TABLE 4

SCORING ON THE EthNic SCALE BY NeIGHBorhood AND ETHNICITY

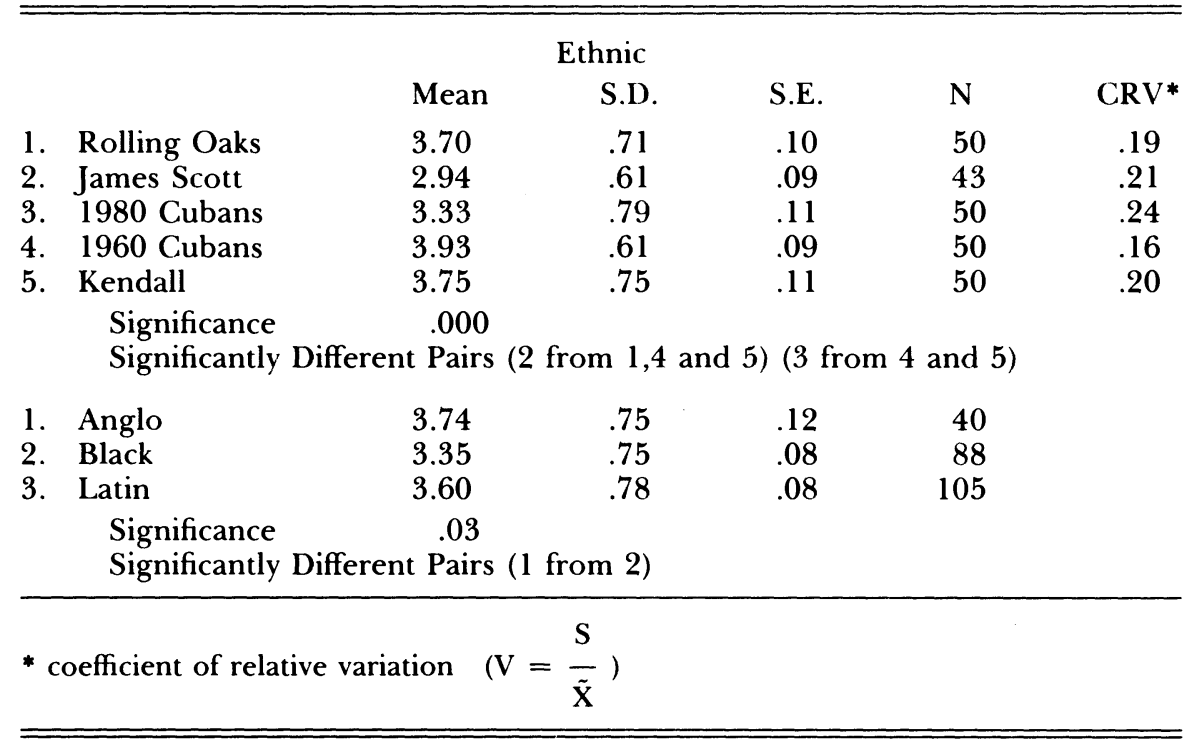

others. The residents of the 1960 Cuban neighborhood responded with the strongest disagreement to ethnic suspicion. There is no significant difference between males and females on this scale and a significant, .003, but weak relationship with family income, with $r=.191$. Anglos are significantly stronger in their disagreement with this idea than are blacks, while Cubans score in-between the Anglos and the blacks.

Analysis of CRVs shows a high level of consensus within neighborhoods on the ethnic suspicion scale when compared to the responses or the other scales. In addition, consensus levels are fairly evenly distributed across the groups.

There exists, therefore, a general disagreement with the idea that ethnic suspicion is justified, except for the residents of the James Scott Housing Project, who generally agree. The 1960 Cubans disagree more than the the residents of other neighborhoods, while Anglos disagree more strongly than any other ethnic group. There exists considerable consensus within neighborhoods on attitudes concerning this practice.

In Table 5 the scores on the scale testing for agreement or disagreement with active patrol strategies is summarized. There is considerable variation among groups concerning agreement with these strategies. In fact, there is more variation among groups on this 
TABLE 5

Scoring on the Patrol Scale by Neighborhood AND ETHNICITY

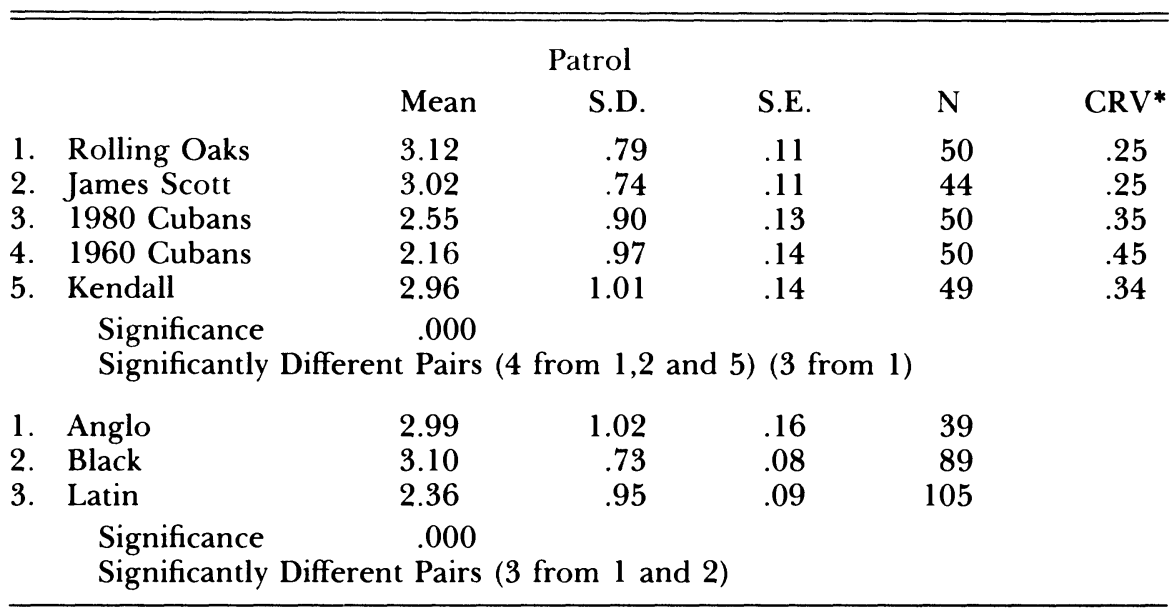

* coefficient of relative variation $\left(\mathrm{V}=\frac{\mathrm{S}}{\tilde{\mathrm{X}}}\right)$

scale than on any of the other four scales. This scale also has the lowest level of consensus within neighborhoods, as demonstrated by the CRV analysis. The first wave of Cuban entrants in 1960 approve of active patrol strategies more than any other group. The 1980 Cuban entrants also approve of these strategies, but not as strongly as their earlier cohort. Finally, Kendall residents weakly agreed with active patrol strategies, while Rolling Oaks and James Scott disagree with these strategies.

There are no significant gender effects. Family income is significantly related to scores on this scale, .040 , but the relationship is weak, with $\mathrm{r}=.120$. When combining all the samples together, it is the Cubans who stand out as different from the other ethnic groups. They agree that active patrol strategies are appropriate, while blacks and Anglos score, on an average, near to the undecided category. However, this does not mean that residents do not have opinions on active patrol strategies. Analysis of the CRVs indicates that there is a considerable lack of consensus within groups on this procedure for the black neighborhoods and Kendall residents. For example, residents of the 1960 Cuban neighborhood exhibited the highest level of agreement with active patrol strategies, but they had considerable disagreement within their group. This is demonstrated by 
the CRV of .45, which is the highest CRV for any neighborhood on any scale.

In sum, attitudes about active patrol strategies vary considerably among the five neighborhoods. The 1960 Cubans had the strongest agreement with active patrol strategies, but the weakest consensus. While the 1980 Cubans agreed with the strategies, they were not as strong in their agreement as the 1960 Cubans. Cubans agreed with active patrol strategies, differentiating themselves from Anglos and blacks who did not.

It is also instructive to assess the level of consensus for each neighborhood across the five scales, to indicate the general level of consensus within each neighborhood. Do certain neighborhoods have a greater degree of agreement on their general feelings about the police and police practices? The 1960 Cubans had the highest average CRV, equalling .31, indicating the weakest level of overall consensus. They also had the most extreme attitudes on many of the police practices. They showed fairly strong consensus on the demeanor and ethnic scales, but the weakest levels of consensus on the three remaining scales. Kendall residents reached a very high level of consensus on three of the scales, demeanor, responsibility and ethnic, but showed some disagreement on the discretion and patrol scales. Residents of both the black neighborhoods, Rolling Oaks and James Scott, had fairly even levels of consensus across the scales. The 1980 Cubans were moderate in their levels of consensus across all five scales when compared to the other four neighborhoods.

\section{Discussion and Conclusions}

It is very clear that there is more variation on attitudes toward police practices among neighborhoods than within the neighborhoods. In fact, a surprising degree of consensus was found within neighborhoods. In all of the scales, with the exception of the demeanor scale, there is enough variation among neighborhoods to suggest a need for differences in police practices, in at least one of the neighborhoods.

Variation on the responsibility scale indicated that it is believed by residents of the Cuban neighborhoods that crime control is mainly a police matter and that there is very little that citizens can do to help. In contrast, Kendall residents had the strongest disagreement with this notion. Residents of the middle-class Kendall area are heavily involved in Citizen's Crime Watch and similar programs that activly involve citizens in crime control. Obviously, the 
police need to approach crime control in each of these areas in a different manner. They will receive much more help and support in the Kendall area, but should begin to change the attitudes of the Cuban residents by educating them on how they can help the police control crime more effectively. The fact that the Cubans had higher levels of disagreement over this idea than any of the other groups leads to the belief that a significant change in attitudes could take place.

Analysis of responses to the discretion scale suggests that there is a greater degree of support for using discretion in applying procedural safeguards in the neighborhood comprised of 1960 Cuban immigrants than in other neighborhoods. Cubans apparently conceptualize a greater degree of latitude than others in applying police procedures, whereas middle-class blacks tend to be more skeptical of the ability of the police to use discretion without ethnic discrimination. Procedural safeguards need to be strictly adhered to in the black areas if the police expect to gain any degree of citizen cooperation and support.

The variation of the scores on the ethnic scale indicate a different grouping of neighborhoods than was found on the other scales. The residents of the James Scott housing project and the 1980 Cubans, to a lesser degree, are the only groups that did not show significant disagreement with the appropriateness of ethnic suspicion. It is ironic that they are not strongly opposed to it, because residents of these two neighborhoods are the most likely to be victims of ethnic suspicion in Miami. Apparently, the majority of the residents in these neighborhoods are law-abiding citizens living in high crime areas. These residents call for more and tougher police protection. It may be that they view, first hand, the extent of the crime and violence in their neighborhoods and believe that there is some justification for ethnic suspicion. It is interesting that the more successful and established counterparts to each of these neighborhoods, the middle-class blacks and the 1960 Cuban entrants are at the opposite end of the continuum. They expressed the strongest disapproval of ethnic suspicion. Perhaps residence in their safe neighborhoods has shifted their concerns from safety to ending discrimination. These differences reflect a need for different police strategies in the different neighborhoods.

Analysis of the responses to the scale on active patrol strategies indicates that there is more variation on this scale than on any of the others. The 1960 Cuban entrants report considerable agreement with active patrol strategies, as do, to a lesser degree, the 1980 Cubans. Middle-class blacks, such as those residing in Rolling Oaks, 
report the strongest disagreement with active patrol strategies. The active strategies gain more support and cooperation in the $1960 \mathrm{Cu}$ ban neighborhood and in the 1980 Cuban neighborhood than in the other neighborhoods. These same strategies, however, would cause some concern in the middle-class black neighborhood. The police may be more effective if they find some alternative strategy for this neighborhood.

Of course, there are other police practices that need to be included in future analyses of community policing. However, this limited study has demonstrated that significant neighhorhood differences do exist concerning attitudes toward police practices, which is evidence for what Sherman has called a mixed strategy approach to policing. ${ }^{24}$

From this study, it appears that neighborhood differences that are significant to policing go beyond traditional ethnic distinctions. The analysis of differences among general ethnic groups, as opposed to analysis of specific neighborhoods, reveals very little. The few exceptions, with differences falling along general ethnic lines, appeared when the two Cuban neighborhoods or the two black neighborhoods held the same general values toward specific police practices. However, this agreement cannot be taken for granted. It appears that the main factors that define neighborhoods, for policing purposes and, as a result, for this study, are ethnicity and socioeconomic status. The various combinations of these two factors seem to generate specific neighborhood climates or cultures that influence attitudes toward policing practices.

Of course, this research is just a beginning. However, this type of empirical data is important due to the recent advent of interest in instituting community policing strategies. ${ }^{25}$ Many times the police develop new strategies, out of necessity, without adequate information to know if such strategies will work. Before the police embrace community policing changes, social scientists need to provide them with an adequate data base.

24 Sherman, supra note 5 , at $379-81$.

25 See Alpert \& Dunham, Community Policing, 14 J. Pol. Sci. \& Admin. 212-222 (1986). 


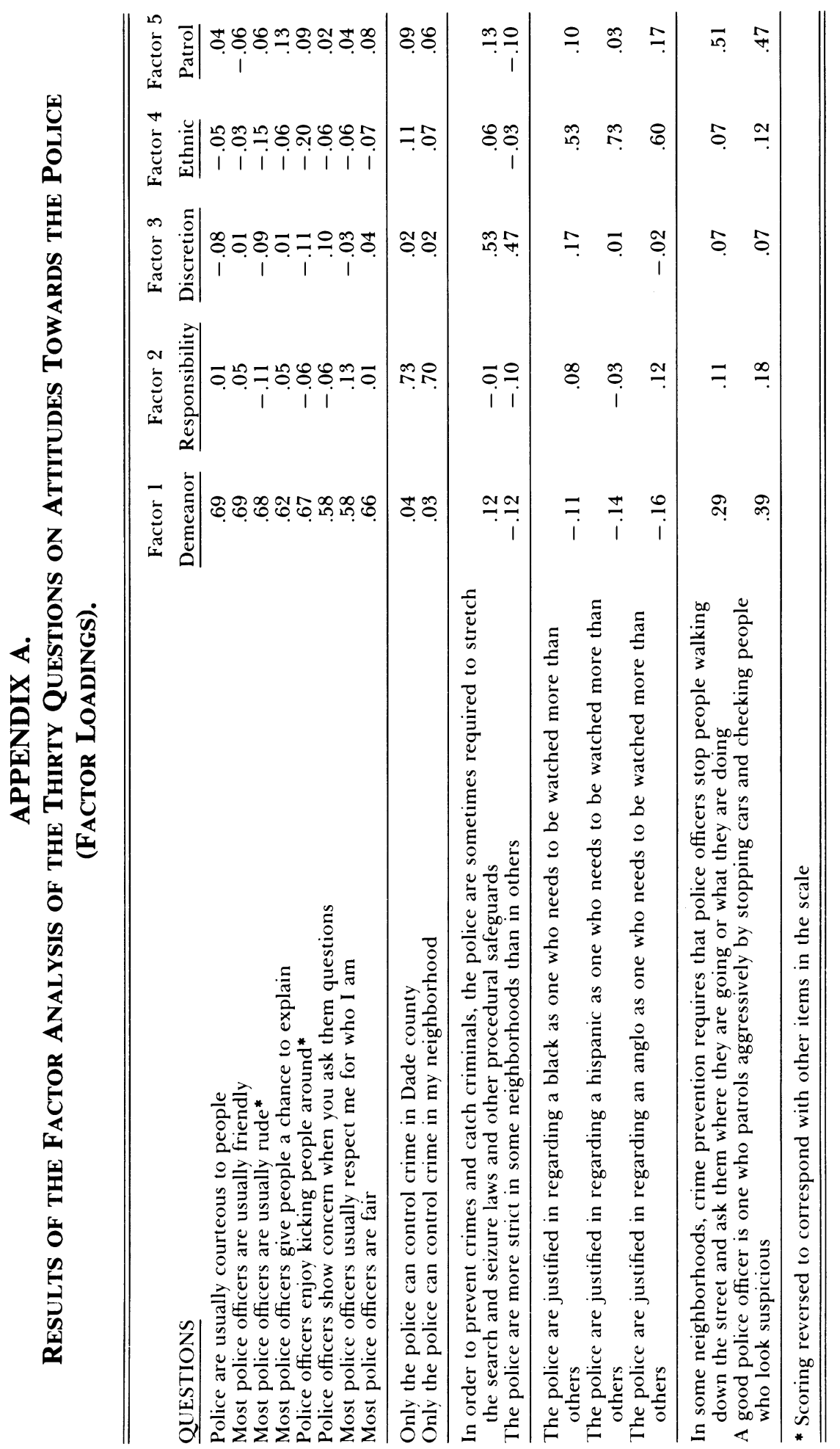


APPENDIX B.

INTER-ITEM CORRELATION FOR DeMEanor Scale

\begin{tabular}{|c|c|c|c|c|c|c|c|c|}
\hline & $\underline{1}$ & $\underline{2}$ & $\underline{3}$ & $\underline{4}$ & $\underline{5}$ & $\underline{6}$ & $\underline{7}$ & $\underline{8}$ \\
\hline Friendly & - & & & & & & & \\
\hline 2. Courteous & .46 & - & & & & & & \\
\hline 3. Rude & .46 & .50 & - & & & & & \\
\hline 4. Enjoy Kicking People Around & .34 & .51 & .52 & - & & & & \\
\hline 5. Give Chance To Explain & .60 & .59 & .52 & .50 & - & & & \\
\hline 6. Fair & .43 & .56 & .42 & .44 & .53 & - & & \\
\hline 7. Show Concern & .39 & .44 & .44 & .45 & .55 & .44 & - & \\
\hline 8. Show Respect & .40 & .46 & .37 & .51 & .50 & .45 & .49 & - \\
\hline
\end{tabular}

